\title{
CAN YOU FEEL YOUR LANGUAGE? AN EXPLORATION OF INDIGENOUS UR- BAN LANGUAGE LEARNING AND THE RESTORATIVE POSSIBILITIES FOR MIND, BODY, AND SPIRIT
}

Ferrin Yola Willie 1

Kwakwaka'wakw \& Haítzaqv

Kwakwala language learner, University of Victoria

\begin{abstract}
Indigenous peoples in Canada maintain beautiful and diverse languages and cultures. Despite the devastating impact of colonization, Indigenous people continue to value their connection to their respective languages and cultures. Due to colonial influences, there are significant numbers of Indigenous people living in urban areas across Canada. Many have relocated from their ancestral communities to pursue education, career, and other opportunities not found within the homelands. This paper explores the challenges, but also the positives and possibilities for the future of urban language learning. It also investigates the restorative possibilities of language learning for the mind, body, and spirit of urban Indigenous language learners, with a particular focus on the Kwakwaka'wakw or Kwakwala speaking peoples of $\mathrm{BC}$. The following questions guide this paper: Is it possible to learn Kwak'wala and truly understand Kwakwaka'wakw perspective while living outside of Kwakwaka'wakw territory? Is it possible for language learning to have psychosomatic, physiological, and possibly supernatural responses, thus "feeling your language"? Through an examination of relevant literature and personal experiences, I explore these related possibilities. An exploration of the influences of language learning on the mind, body, and spirit and have shown that language learning, in at least a few cases, is showing promise to have transformative properties empowering a learner to "feel the language."
\end{abstract}

Keywords: urban Indigenous language learning; land-based learning; Kwakwaka’'wakw; Kwaḱwala language; Indigenous healing

Citation: Willie, F. Y. (2021). Can you feel your language? An exploration of Indigenous urban language learning and the restorative possibilities for mind, body, and spirit. WINHEC: International Journal of Indigenous Education Scholarship, 16(1), pp. 210-238. http://dx.doi.org/10.18357/wj1202120287. Special Issue on Indigenous Language Revitalization: Innovation, Reflection and Future Directions, Guest Co-Editors Drs. Onowa McIvor and Kari A. B. Chew.

1Ferrin Yola Willie, University of Victoria; yola@uvic.ca 


\section{Introduction}

Indigenous peoples in Canada maintain beautiful and diverse languages and cultures. Despite the devastating impact of colonization, Indigenous people continue to value their connection to their respective languages and cultures. Due to colonial influences, there are significant numbers of Indigenous people living in urban areas across Canada. Many have relocated from their ancestral communities to pursue education, career, and other opportunities not found within the homelands. Indigenous language initiatives such as introductory language classes are occurring in many of these urban centres. This paper explores the challenges, but also the positives and possibilities for the future of urban language learning. It will also investigate the restorative possibilities of language learning for the mind, body, and spirit of urban Indigenous language learners, with a particular focus on the Kwakwaka'wakw or Kwakwala speaking peoples of BC. To guide this paper, the following questions will be explored: Is it possible to learn Kwakwala and truly understand Kwakwạkạ'wakw perspective while living outside of Kwakwaka ${ }^{\prime}$ 'wakw territory? Is it possible for language learning to have a psychosomatic, physiological, and possibly supernatural effect, thus "feeling your language"? I will examine relevant literature and draw on personal experience to explore these related possibilities.

\section{Background}

\section{Urban Indigenous Populations}

In Canada, just over 50 percent of band registered Indians are living off reserve in urban and other rural areas, and this does not include non-status Indians, Métis, and Inuit urban popu- 
lations (Statistics Canada, 2016). This shift of Indigenous peoples from their ancestral territories to other locations is largely due to colonial influence, and further reasons for this movement include forced relocation, education and career pursuits, economic prosperity, and adequate housing. The impacts of colonization are felt strongly within Indigenous communities and many have left their respective ancestral lands in pursuit of a better life for themselves and their families.

The traditional territory of the Kwakwaka'wakw (the Kwakwala speaking people) encompasses the area around the northern tip of Vancouver Island and the surrounding mainland along the coast of $\mathrm{BC}$. There are currently 14 to 16 tribes belonging to the Kwakwaka'wakw Nation, and only a few of these tribes remain in their original villages. Many of the Kwakwạa ${ }^{\prime} w a k w$ ancestral sites have been abandoned, and tribe members have relocated to nearby locations. It is my understanding, as a Kwakwaka'wakw member, that the majority of our population are now living in urban environments.

The Dzawada' enuxw, one of the Kwakwaka $\underline{a}$ 'wakw tribes, are one of the few remaining within their original territory. The Dzawadá'enuxw band membership totals 600 approximately with only 60 remaining in the village of Ukwanalis (Kingcome Inlet) meaning 90 percent are living outside of the community and many in urban centres. Of the 60 members living in Ukwanalis, there are only one or two first-language Kwakwala speakers remaining. These speakers are elderly and unable to consistently teach or share their language knowledge within the village. 


\section{Kwaḱwala Language Loss}

The Kwakwaka ${ }^{\prime}$ wakw presently have a 2.2 percent population of first-language proficient Kwakwala speakers (Dunlop et al., 2018). The majority of these speakers are elderly, and to my knowledge, none of our Kwakwakaa'wakw children can speak the language proficiently.

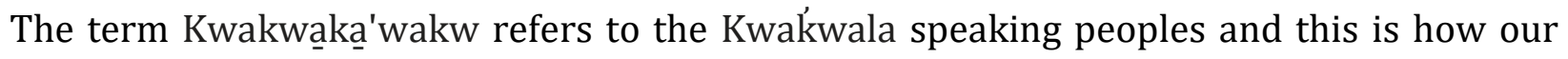
people define themselves as a Nation. So then, what happens when all the speakers are gone? This could foreseeably happen within the next decade or even within the next five years in some communities such as my ancestral village of Ukwanalis (Kingcome Inlet) or the Kwagu’ł village of Tsaxis (Fort Rupert). I keep wondering, will our people still refer to themselves as the Kwakwaka'wakw? Or like the pop star Prince, will they become known as "the

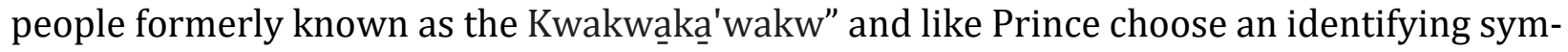
bol instead?

\section{Kwaḱwala Language Renewal}

The following describes the state of the Kwakwala language:

Over the last two decades there have been occasional outbreaks of enthusiasm and opportunity in the form of Kwakwala teacher training, curriculum development and funding for additional positions and new technologies. But, in truth, and it's a time for truth, the history of Kwakwala renewal has largely been an account of teacher burnout, student stagnation, and community disillusion in which everybody just gave the whole responsibility for language maintenance to the schools. And school programs have been unsuccessful in teaching the students to speak Kwakwala fluently; and the fluent speakers have grown older and fewer; and there is now little incentive to learn 
the language because it is seldom used outside the gukwdzi ('bighouse'). (Anthony et al., 2003, p. 3)

This description still stands as a fairly accurate account of the current Kwakwala language situation in 2021. My recent experience of living in the Kwagu'ł community of Tsaxis, participating in Kwakwala language learning groups, and working in numerous schools in the surrounding area as a counsellor for five years has provided me with insight into the current language situation. Kwakwala continuity is largely a community expectation of the elementary schools within the Kwakwaka'wakw communities. The schools each have one or two language and culture teachers who typically spend no more than one hour per day with students. During this time, the teachers are expected to facilitate both language and culture programs (an entire potlatch program of traditional songs and dances). It seems these teachers are often stretched to capacity, with minimal support and insufficient resources or curriculum to follow. These "language exposure" programs offered through the schools have yet to produce any proficient speakers. Kwakwala is seldom spoken outside of the gukwdzi (bighouse, where potlatches and other traditional ceremonies take place) and even then, less and less Kwakwala is spoken in the gukwdzi during potlatches and other cultural events as many of the newer gigame' (chiefs, cultural leaders who are the main speakers during potlatches and other cultural ceremonies) are not able to speak Kwakwala.

\section{Importance of Language Connection and Honouring the Language of the Land}

There is much evidence to suggest that many Indigenous peoples value their mother tongue and believe language continuity is important (FPCC, 2016; NAFC, 2018; OFIFC, 2015). Language connection can be especially important to urban Indigenous populations as it links 
them to their homelands, communities, families, and cultural practices. Ancestral language learning can also offer an opportunity for healing and connection to land. Wildcat et al. (2014) argue that land-based education is essential to decolonization and that "decolonization must involve forms of education that reconnect Indigenous peoples to land, the social relations, knowledges and languages that arise from the land" (p.1). In a similar article, the authors express the importance of land-based learning involving Indigenous worldview and educational practices that encompass traditional ecological knowledge and encourage responsible care for the land (Bang et al., 2014).

Urban concepts of Indigenous identity are also significant as individuals encounter differing cultures and perspectives in city centres. Indigenous urban identity may be a different experience from those who remain within the homelands surrounded by family and community. No matter the location, having a strong sense of identity helps one move along confidently in life's journey and a connection to ancestral language supports this (Child, 2016; Erasmus, 2019; Hallet et al., 2007; Thompson, 2012).

Also, of importance is an honouring of the language of the land you are located on. In her article titled “We Can't Feel our Language," Natalie Baloy discusses the importance of making space for language learning in the city as well as the concept of "placing language," which involves an honouring of the local languages. As Baloy suggests, this is an important part of urban language learning; however, establishing a protocol with the language keepers of the 
land and requesting guidance is also imperative. I believe the likelihood of a genuine language learning experience is greater if this acknowledgement and some learning of the land's ancestral language takes place.

As a Kwakwaka' wakw member living in the territory of the Snuneymuxw (city of Nanaimo), I am aware of the protocols involved when conducting cultural work in another Nation's territory. It is customary on Vancouver Island to acknowledge the traditional territory and people of the land before conducting any cultural practices, and I believe language work is included in this protocol. As our family moves forward in our language-learning journey in Snuneymuxw territory, I believe it is important to follow protocol and acknowledge the Nation and territory as well as the Hul'q'umin'um' language (ancestral language of the Snuneymuxw land and people). I also maintain it is important to reach out to those involved in Hul'q'umin'um' language revitalization for mutual support and guidance, especially if wanting to incorporate land-based learning. Doing so will help provide a language-learning experience that encourages an understanding of not only Kwakwaka'wakw, but also Snuneymuxw perspective and Indigenous worldview.

As part of a land-inspired Facebook project I am facilitating, I have reached out to a local Hul'q'umin'um' language teacher in Snuneymuxw to join the initiative. I have invited her to share with us the Hul'q'umin'um' words for what we are sharing out and the place names for the various locations we are sharing out images and videos from in Hul'q'umin'um'. It seems we are in the beginning stages of this work together, and I appreciate this connection and look forward to potential future collaborations. It does not feel like this effort to honour the 
ancestral language of the land takes away from my Kwakwala work, but rather adds to it. Honouring the Hul'q'umin'um' language and the lands of Snuneymuxw I am living and learning on has enlightened my Kwakwala learning journey greatly.

\section{Challenges for Urban Language Learning}

The complexities of learning an Indigenous language, especially one that is endangered, are obvious to me as I attempt to learn my ancestral Kwakwala language in Snuneymuxw territory and it seems many of these challenges are found across urban and non-urban contexts.

Minimal access to speakers is a major obstacle for urban language learning (while acknowledging this can also be an issue for non-urban contexts). The Kwagu’ł community of Tsaxis (Fort Rupert) has at least five proficient Kwakwala speakers engaged in language work, but in comparison, the Dzawadạ'enuxw community of Ukwwanalis (Kingcome Inlet) has none. Our Kwakwala language learning community group in Snuneymuxw, until recently, had one firstlanguage Kwakwala speaker consistently supporting the weekly sessions over the past year. At our last session before the last holiday break, a special event celebrating our language work, a total of five speakers attended and indicated they would like to support our group in the New Year. It was exciting to have these speakers on board and our community group was gaining momentum until the onset of Covid-19, and since then we have not been able to meet, and our group learning is at a standstill.

The majority of Kwakwala first-language speakers living in urban areas have been away for a lengthy amount of time and have not had the opportunity to speak their language on a daily 
basis. This is the case for the five Kwakwala speakers involved in our language work in Snuneymuxw. Thus, urban first-language speakers may require time to reawaken their language speaking ability in order to best support second-language learners. In a recent personal com-

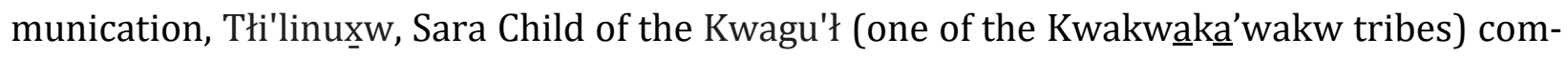
munity of Tsaxis (Fort Rupert), revealed the speakers she has been working with are "still remembering words from when they were children," and are thus still in the process of reawakening the language even after 10 years of engagement in Kwakwala language revitalization work.

Many urban Indigenous populations are keen to learn their language but unable to attend classes due to poverty issues. The Ontario report on Language Transfer Practices in Urban Indigenous Communities highlight how urban community language classes are inconsistently attended and this is correlated with the general impoverished state of participants (OFIFC, 2015). These challenges include issues such as transportation, as many Indigenous families living in the city do not own their own vehicle and rely on public transportation. This was apparent during my time at an Indigenous community services organization in Victoria, where I worked with Indigenous families for five years. This is also a recent occurrence for families who are struggling to attend our Kwakwala learning group in Snuneymuxw. Busing across the city with children in the evening (a typical time for urban community classes) can be difficult. This prevents many urban Indigenous families from attending urban community events and programs, such as language classes. 
Until recently, there were no funding sources available specifically for urban language-learning initiatives in BC. The First Peoples' Cultural Council (FPCC) addresses this in their report, which states "there is often no particular funding pot to enable Indigenous language acquisition and maintenance in urban settings" (2016, p. 29). Community groups in urban settings have typically come together with little or no funding. While there seems to be an understanding that everyone wants to learn and share for the sake of the language, it is difficult to do so without funds to pay for space, transportation, and nourishment. It is also difficult for first-language speakers and facilitators to make a commitment without some sort of compensation. This is due to the reality of westernized living, where we are required to earn an income to pay for the high costs of our livelihood in the city.

The FPCC also states "other challenges include addressing the needs of language groups who are some distance from their homeland" (2016, p. 30) as an issue for Indigenous urban language learning. It seems the further the distance, the greater the challenge in finding firstlanguage speakers to support language learning, at least this has been the case for the Kwakwala groups I have participated in. Also, if located outside of ancestral homelands and in the territory of a different Nation, protocols may need to be considered in acknowledging the Indigenous peoples of the land and their respective language. I discuss this concept of "placing language" put forward by Natalie Baloy earlier in this paper.

Dialect differences can be problematic for urban groups whose members are from varying dialects within a language group (again acknowledging that this also occurs in communities; however, it is often a factor in urban contexts). Also, older and newer versions of particular 
words and phrases may arise, and these differences can also be tricky to navigate for learning groups (OFIFC, 2015). At times, even within the same dialect there can be vast differences. As an example, our group in Snuneymuxw was recently searching for the Kwakwala word for scarf. I found Tłaxxu' on the First Voices website, which was obtained from 'Yalis (Alert

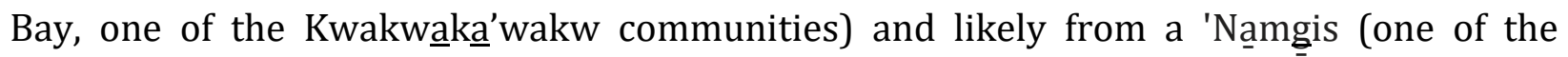
Kwakwaka ${ }^{\prime} w a k w$ tribes whose current village is located in Alert Bay) speaker. One speaker of the Dzawadán 'enuxw (another Kwakwaka $\underline{a}$ wakw tribe) dialect was not familiar with T'łaxu' and put forward Sabaxtłe for scarf (also commenting that First Voices is often "wrong"). In the same session, another speaker of Dzawada'enuxw dialect shared privately with me that Sabaxxtłe refers to a scarf or kerchief worn over the head and instead gave the word Kann'xawe' for a scarf worn around the neck. Later when Kann'xawe' was put forward to the group, the first Dzawadą'enuxw speaker disagreed and indicated Kann'xawe' is not a scarf but a tie worn around neck. This scenario is not an uncommon experience in language learning across, or even within, dialects.

A lack of adequate language learning resources can be an issue for language-learning groups in both urban locations and in the homelands. Space issues can also be of concern, particularly to urban groups who do not have rent-free access to community buildings as they might in their home communities. While there are many obstacles to overcome in urban Indigenous language learning, there are also some optimistic components and current strategies that are working well in the field. 


\section{Positives and Current Strategies in Urban Language Learning}

Introductory language-learning groups can provide opportunity for those who have never heard or had any previous access to learning the language (FPCC, 2016). These urban language initiatives can also connect learners with others of the same ancestry, and this can be meaningful for those who have never been to their home community, as well as those who are living away. This connection to identity can be valuable for Indigenous urbanites and "sometimes can provide a more supportive environment than in a reserve community" (FPCC, 2016, p. 29).

Another strategy in urban language learning is the Mentor-Apprentice Program (MAP) which requires only two people, and is not bound by residence (Hinton, 2001), thus providing an opportunity for individuals to learn their language in urban centres. This report by FPCC also highlights a MAP team as a "success" where an urban community group formed around a Mentor-Apprentice pair (FPCC, 2016). In a Kwakwala language group I attended from 2012 to 2013 in Victoria, a MAP team was the driving force of our group. Recently, my mentor and I, as a MAP team, have been a crucial part of our Kwakwala learning group in Snuneymuxw. A former MAP team is also currently integral to the Kwakwala course currently offered through North Island College in Courtney, BC. Thus, MAP teams can strengthen other urban community programs.

As a recent response to Covid-19, language groups are taking advantage of Facebook to support community learning at a distance, which provides an additional opportunity for urban learners. Previously, Facebook was mainly utilized by various Indigenous language-learning 
groups to coordinate activities (FPCC, 2016). Facebook is also used to share resources, post forums for language discussions, and share popular memes.

Memes are humorous images, videos, or pieces of text that are copied (often with slight variations) and spread rapidly by Internet users. Recently a Mohawk language learner and teacher, Tehakanere John Henhawk, was recognized for his efforts in creating and sharing Mohawk memes on social media. Henhawk says, "Everyone knows what memes are. We want the language to be seen, heard and to be used." He goes further to say, "you never know how that's going to affect somebody. Sometimes the smallest thing can inspire someone to at least look into the state of Kanyen'kéha and then maybe develop interest into helping make it stronger" (Deer, 2019, p. 1).

Facebook is used by several Kwakwala learning groups to coordinate activities, share resources, and discuss Kwakwala-related topics. Facebook memes have also become a fun way to share the Kwakwala language and are regularly posted and quickly shared by numerous Kwakwạka'wakw members. Facebook has also become better utilized by various Kwakwala communities to support learning at a distance (with the current Covid-19 situation). All of these uses of Facebook, ranging from coordinating activities to learning at a distance, are beneficial strategies for urban language learning.

First Voices and YouTube (live action/animated videos in language) are also popular resources for urban language learners. In addition, FaceTime and Skype are useful for connecting with mentors (first-language speakers) and "it is important to remember that a telephone 
can enable a conversation in the language" (FPCC, 2016, p. 30). Along with these positive aspects of Indigenous urban language revitalization, there are also promising approaches for the future, including social media platforms.

\section{Future Strategies in Urban Language Learning}

A valuable concept uncovered in this exploration was that of equal opportunities for urban Indigenous peoples to learn their language (FPCC, 2016). In order for this to happen, consistent and adequate funding sources need to be available and equally support both urban and non-urban language-learning initiatives.

The National Association of Friendship Centres (NAFC) refers to the importance of "safe spaces where people are not afraid to fail or speak without being judged" (2018, p. 15). Safe learning spaces are crucial to all learning, including urban and non-urban Indigenous language learning. Creating and encouraging safe spaces for Kwakwala learning is essential to my language-learning journey both as a teacher and learner. As an Indigenous counsellor working within the school system in both urban and non-urban settings, I came to understand the fundamental importance of a safe environment for genuine learning. The Indigenous children and youth I worked with required safe environments where their socio-emotional needs were cared for in order for them to meaningfully engage in their learning at school. I believe it is the same for all learners no matter the age or context.

The potential for new digital technologies and online platforms to support urban language learning is promising (Carpenter et al., 2017; Galla, 2016). Indigenous radio also has great 
potential for supporting Indigenous language revitalization movements in urban and nonurban contexts (UNESCO, 2019). As an example, the Homalco First Nation (currently located in Campbell River, BC) recently launched a radio station with the intent to provide languagelearning opportunities for their membership. Darren Blaney, an elected councillor for the Nation, is hopeful "that six hours a week of K'omoks-language programming will help reverse the decline of the indigenous language and introduce it to a new generation" (Wilson, 2016, p. 1). Technology can also provide "a less intimidating venue for the learner" (Galla, 2016, p. 1144) or an alternative method for practicing pronunciation without fear of critical feedback. Lastly, creating new words for urban and modern living would also be beneficial for the forward movement of Indigenous urban language learning.

As an urban language learner, I have found there are areas where no Kwakwala exists, such as vehicles, city housing, and food groups found at the grocery store. The only reference for vehicle is the word for tires, and this limits our ability to talk about the diversity of current vehicles, especially in the city. There seem to be few words available to refer to the different types of modern housing, such as apartments and the high rises found in the downtown core. There are minimal words to talk about the wide range of foods in the grocery store and on our dinner tables. For example, Kwakwala has few words referring to fruits and vegetables, and so the general words used refer only to "something sweet to eat" and "something that grows from the ground." There are some Kwakwala-ized (as I call them) versions of English words available for fruits and vegetables, such as payas for pears or con for corn. However, I personally would prefer a Kwakwala word that describes the food item as is the way of our 
language (descriptive). Creating new words for modern day use, in my experience, is imperative to language continuity for both urban and non-urban learners but may be of greater importance for those in the city. Regardless of the ongoing challenges to language learning for Indigenous learners in both urban and non-urban areas, there are numerous possibilities to support future learning. This discussion of future strategies leads to the concept of landbased learning and its importance to Indigenous language revitalization but also the challenges particular to urban learners.

\section{Land-Based Language Learning}

Land-based learning is a concept that often surfaces in the current field of Indigenous language revitalization and is significant for urban language learning endeavours. Many Indigenous language warriors and teachers maintain land-based learning is integral to the resurgence of their respective language. Many believe language is connected to their lands, and for language learning to be authentic, opportunities for learning language out on their ancestral territories should be provided (Child, 2016; Erasmus, 2019; Kahtehron:ni, 2019; Rorick, 2019; Rosborough \& Rorick, 2017). In her thesis, Awi'nakola: We are one with the land and sea (Igniting the fire within: Youth leadership camp framework), Child emphasizes the importance of language learning on the land. Child believes a restoration of Indigenous wellness is possible but, "only if it occurs within our traditional territories because this is where our wellness springs from; this is where our ancestors come from; this is where our language shaped our worldview through relationships with the land, sea, and our ancestors" (Child, 2016, p. 52). In connection to this, Kahtehron:ni suggests a kincentric approach to community language planning and future language revitalization efforts in her thesis (Kahtehron:ni, 
2016). This concept of self and nature as part of an extended ecological family that shares ancestry and origins also refers to the important connection between Indigenous language learning and ancestral territory. Kahtehron:ni says an intergenerational community approach to language revitalization "creates a path to healing by reclaiming, rebuilding, and recovering what we were once denied" (Kahtehron:ni, 2016, p. 66). In her thesis, Erasmus (2019) also puts forward the need for immersive language learning to take place on the land in order for learning to be authentic.

Land-based language learning is something aspired to by Indigenous language learners and teachers; however, it can be a challenging task especially for urban members living away from the lands of their ancestral language. Many urban Indigenous members are consumed by their day-to-day requirements of providing a home, food, and clothing for their families as well as working through the residual effects of the colonial system. Therefore, the ability to travel back to their home communities for language learning opportunities on their ancestral lands is compromised.

It is my impression many language champions envision land-based language learning as programming that involves bringing participants out on the land to origin sites, to traditional food harvesting locations, and incorporates traditional harvesting practices and so on. This type of teaching and learning is difficult for those in urban areas away from their ancestral lands to carry out as they do not have the rights to visit these locations or for harvesting in their lived area. As these sites may not be a part of an urban learner's ancestral history, learning about them may also be irrelevant. 
Also, bringing Elder first-language speakers out on the land is not a possibility for many due to age, limited mobility, and health issues. So, land-based learning initiatives may need to take place without first-language speakers who are usually the best resources for language learning, and there may not be many Elder first-language speakers available in the first place in an urban setting.

Although difficult, land-based learning can offer many positives to language learners. In my recent experience as an urban learner and as a response to Covid-19, I have initiated a landinspired project with a couple members of our Kwakwala learning group in Snuneymuxw (Nanaimo). Each of us share out at least two posts per week on Facebook related to landbased learning. These posts can be a video or image with audio, including the Kwakwala word for the plant, animal, or outdoor life and also include an acknowledgement to the ancestral lands where the learning took place (or where the photo/video was taken). This landinspired project has been a meaningful learning experience for all involved. Not only are we learning the Kwakwala words as individuals and as a small group, but we are also sharing these out to encourage others to learn. It has been a way for us to learn Kwakwala and connect with the ancestral lands of the Snuneymuxw we are living on.

Another example is the calendar project I am facilitating on Facebook (also in response to Covid-19). This Kwakwala project involves a daily calendar share from one of the seven participating families including the date (day of the week, month, and date). Kwakwala months were named in relation to what was growing or available for harvesting on the lands and waters in our territory at the time. For example, August is Xamsxamsdi and refers to the 
emptying of fish storage boxes. The three months previous are related to the berries that would have been growing or the time we would have been picking these berries. Kamkáamdzakikwanx (salmon berry time) is how we refer to May, Gwagwátanx (red huckleberry time) for June, and Ninakwanx (salal berry time) for July. Due to this project, I am now paying attention to and teaching my children about what is growing around us or what we would have been harvesting if living in the homelands. This calendar project encourages all participants to tune into the plant life around them and thus supports a connection to the land even though most are in urban locations. This calendar project also includes a word of the day component where each family chooses their own word and some families are choosing to do their videos outdoors with words related to the natural world. One family in particular has gone out searching in their urban area for such things as clams, starfish, and blackberries for their word of the day and to record their video from that location.

The last Facebook initiative I have been overseeing is a weather project involving a few households from within our family. In this activity, parents record short conversations with their children about the weather. I have also been sharing photos with accompanying phrases to do with the weather. This project encourages everyone involved to get outside to best learn about the weather and supports a connection to mother nature. It is exciting for our household when the weather changes, as we then have new stimulus for our learning!

All of these projects have been incredibly helpful to my personal language-learning journey and an unexpected but great way to conduct land-based learning in an urban setting. I have 
been taking photos and videos practicing my Kwakwala learning while out running in various locations in Snuneymuxw. I share many of these photos and videos out on Facebook as part of our projects. It has become a highly enjoyable time for me to get out for some alone time, exercise, fresh air, and to capture the plant and animal life and weather occurrences I am encountering. It encourages me to get out for exercise more often and also has me paying attention to what is growing in these locations. I am learning about plant life in a way I have never learned before. I do not know the names of many of these plants in English, and so it is exciting to learn them in Kwakwala first! I am also appreciating the creatures I cross paths with, such as deer, turtles, centipedes, worms, and even slugs are now exciting! These projects encourage a connection to the natural world in general but also support all aspects of my being and have been a surprisingly effective way to carry out holistic land-based learning in an urban setting.

The obstacles to land-based learning are numerous and more so for urban language learners. However, if these difficulties can be overcome, the benefits would be vast. Traditional ecological knowledge could be gained as part of language learning on the land. Also learning about the traditional place names and origin stories of first ancestors would be significant. This type of language learning opportunity could support a connection to ancestral lands in a way that holistically engages the mind, body, and spirit of those involved. It is my opinion much learning could be gained not only in terms of language acquisition but also worldview perspective and a strengthening of identity, thus providing a genuine language-learning experience. 


\section{Restoration of Kwakwaka'wakw Perspective and Falling in Love with the Language}

In her Master's thesis, Tłi'linuxw, Sara Child (2016) suggests the restoration of Kwakwaka ${ }^{\prime} w a k w$ perspective is possible through the understanding of Kwakwaka'wakw concepts and land-based learning. Tłi'linuxw says, "our distinct language feeds our view of the world and our way of being, it is interwoven with culture, is vital to our personal and collective wellness and is integral to who we are as Kwakwạká'wakw" (p. 1). Tłi'linuxw believes language learning on the ancestral lands of the learner will have restorative benefits for the mind, body, and spirit and will further lead to an authentic understanding of Kwakwạka'wakw perspective. She describes six Kwakwạkạ'wakw concepts (2016), Sạnala (to be whole), Maya'xạla laxus bạkwine' (respect for self), Mu'lanokww (we are grateful), Awi'nakola (we are one with the land and the sea), Maya'xalapa (respect for each other), and O'mann's 'nam'a (we are one), to be used as the basis for Kwakwala learning and leading to a restoration of a Kwakwa $\underline{\text { a }}$ 'wakw way of seeing the world. These Kwakwaka'wakw concepts are examples of the beauty found in the Kwakwala language and exemplify the Kwakwạkạ'wakw worldview.

In her work, the late T'łatłakuł, Dr. Trish Rosborough (2019), Kwagu’ł (Kwakwakaa’wakw) member and Kwakwwala language warrior, also explores the beauty of the Kwakwala language and the deeper meaning of words. T'łatłakuł shares, "speaking Kwak'wala is not just about having translations of things I want to say in English but that I can understand the Kwakwaka'wakw way of seeing the world" (p. 1), thus, speaking to the importance of gaining an understanding of worldview as part of language learning. In my Kwakwala journey, I have deeply appreciated the broadening of perspective and a beginning to seeing the world as my 
ancestors did. The Kwakwala language vastly differs from that of English (my first language) and examples of this include the following: our general reference for cousins is the same as for brothers and sisters (and this aligns with our Kwakwaka'wakw teachings that our first cousins are our brothers and sisters), and there is no way to say "I am sorry," but there is a word for "I am regretful." A point of significance in my learning journey was the realization that the way we ask someone "how is your day?" is the same as how we ask about the weather. This I learned as part of the weather project I am facilitating over Facebook. It is only from this Kwakwala learning that I came to understand how the weather of the day directly impacts how I am feeling. The Kwakwala language reflects and teaches us about this connection between our well-being and the natural world in a way that English does not.

In her doctoral dissertation, T́łatłakuł states, “working to recover Kwak'wala in my own life involves deep personal, interpersonal, and social processes and an untangling of messages carried at a profound level" (2012, p. 14). I believe what T'łatłakuł alludes to is the deeper experiences of learning an ancestral language and the psychosomatic, physiological, and spiritual responses that are possible. I recently had an overwhelming experience as part of my language-learning journey. As I was lying in bed with Kwakwala words running through my mind, I could simultaneously feel my heart beating to the words and other physical responses happening in various parts of my body. To me, it felt as though I was integrating these Kwakwala words into my mind and body, and I also sensed a spiritual awakening. I thought to myself, "I'm feeling my language," and for me this was a profound and similar experience to that of falling in love. 
My Kwakwala language-learning journey began long ago, but it is more recent that I have been actively learning and also teaching my family daily. I am definitely "feeling my language," and I am deeply engaged with Kwakwala. As in any meaningful relationship, there are times when I am overjoyed and other times where I am frustrated or things feel stagnant. My language learning aspirations require a long-term, steady commitment with lots of patience, nurturing, and tender loving care towards myself and the language. It is a journey that encompasses every aspect of my being, and I am grateful I have been able to find ways of engaging in language learning that are holistic, broaden my perspective of Kwakwaka worldview, and connect me to the natural world despite living away from the homelands.

\section{Conclusion}

This paper explored urban Indigenous language-learning with a particular focus on the Kwakwạka'wakw Nation and Kwaḱwala language. As many Indigenous people are residing in cities and other urban locations across Canada, urban language initiatives offer Indigenous peoples the opportunity to learn language, connect with others, and strengthen their identity. There are many challenges for urban language learners but also positive influences, strategies working well, and possibilities for the future. Some of the leading strategies at present are the combined efforts of the Mentor-Apprentice program with other community programming initiatives and the use of social media platforms such as Facebook.

Indigenous language revitalization seemingly contributes to the restoration of Indigenous ways of being, and land-based learning offers a possibility for this. I have questioned whether authentic land-based learning can occur and if an understanding of worldview is possible if 
learning language occurs outside one's ancestral lands. I have come to believe this learning and understanding is more likely if you are engaging with the ancestral language of the land you are on. I also explored the influences of language learning on the mind, body, and spirit and have found that language learning, in at least a few cases, is showing promise to have transformative properties empowering a learner to "feel the language." 


\section{Glossary}

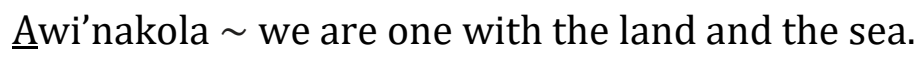

Dzawada'enuxw person or people from Ukwanalis (Kingcome Inlet), one of the tribes of the Kwakwaka'wakw.

Gigame' (chief) traditional leader

Gukwdzi (bighouse) where cultural ceremonies take place.

Gwagwátạnx (red huckleberry time) June

Haíłzaqv the Haíłzaqvịa speaking people of Wáglísla (Bella Bella) on the northwest coast of North America just above the Kwakwaka'wakw.

Hul'q'umin'um' the ancestral language of the Snuneymuxw.

Kamḱamdzakikwanx (salmon berry tome) May

Kwagu'ł person or people from Fort Rupert, one of the Kwakwaka'wakw tribes.

Kwakwaka'wakw the Kwakwala-speaking people on the northeast coast of Vancouver Island and the adjacent mainland coast of British Columbia.

Kwakwala the ancestral language of the Kwakwaka'wakw.

Maya'xala laxus bạkwine' respect for your self

Maya'xalaṕa respect for each other

Mu'lanoknw we are grateful

'Namgis person or people from Alert Bay, one of the Kwakwaka $\underline{a}$ 'wakw tribes.

Ninaḱwanx (salalberry time) July

O'man's 'nạm'a we are one

Sabạxtłe' kerchief

Sạnala to be whole

Snuneymuxw (Nanaimo) refers to the great people.

T́łatłakuł (Trish Rosborough) Kwakwala name 
T’łaxu' scarf

Tłi'linuxw Sara Child) Kwaḱwala name

Tsaxis (Fort Rupert) the village of the Kwagu'ł.

Ukwanalis (Kingcome Inlet) the village of the Dzawadạ'enuxw.

Xamsxamsdi (time of empty fish storage boxes) August

Kann'xַawe' neck ring

'Yalis (Alert Bay) the village of the 'Namgis

\section{About the Author}

Nugwa'ạm Yola...k'aḱkut'łan xan Kwak'wale' - I am Yola... I am learning Kwakiwala. I am also a mother of three, partner to a fellow Kwakwaka ${ }^{\prime} w a k w$, and we are learning our ancestral language of Kwakwala as a family. I am a doctoral student in the field of Indigenous language revitalization with the University of Victoria. I came into this program with intention to create space for learning my language and to explore the connection between language learning and healing. My family and I are currently living and learning on the ancestral lands of the Hul'q'umi'num' language and the Snuneymuxw people. 


\section{References}

Baloy, N. J. K. (2011). "We can't feel our language”: Making places in the city for Aboriginal language revitalization. The American Indian Quarterly, 35(4), 515-548. https://www.muse.jhu.edu/article/453956

Bang, M., Curley, L., Kessel, A., Marin, A., Suzukovich, E.S., III, \& Strack, G. (2014). Muskrat theories, tobacco in the streets, and living Chicago as Indigenous land. Environmental Education Research, 20(1), 37-55. https://doi.org/10.1080/13504622.2013.865113

Carpenter, J., Guerin, A., Kaczmarek, M., Lason, G., Lawson, K., Nathan, L. P., \& Turin, M. (2016). Digital access for language and culture in First Nations communities. University of British Columbia. https://heiltsuk.sites.olt.ubc.ca/files/2016/11/Digital Language Access ExecSummary 2016.pdf

Child, S. (2016). Awi'nakola: We are one with the land and sea, Igniting the fire within; Youth leadership camp framework (Master's thesis, University of Victoria). https://dspace.library.uvic.ca//handle/1828/10159

Deer, J. (2019). Meet the man who is helping revitalize Mohawk language through memes. CBC News. memes-john-henhawk-1.5169484

Dunlop, B., Gessner, S., Herbert, T., \& Parker, A. (2018). Report on the status of B.C. First Nations languages 2018. First Peoples' Cultural Council. https://fpcc.ca/wp-content/uploads/2020/07/FPCC-LanguageReport-180716-WEB.pdf

Erasmus, M. T. (2019). Goyatii k'aat'ii ats'edee, k'aat'ii adets'edee: ho! Healing our languages, healing ourselves: Now is the time (Master's thesis, University of Victoria) https://dspace.library.uvic.ca/handle/1828/10855

First Peoples' Cultural Council (2016). Indigenous language recognition, preservation and revitalization: A report on the national dialogue session on Indigenous languages. http://www.fpcc.ca/files/PDF/General/FPCC_National_Dialogue_Session_Report_Final.pdf

Hallett, D., Chandler, M. J., \& Lalonde, C. E. (2007). Aboriginal language knowledge and youth suicide. Cognitive Development, 22(3), 392-399. https://doi.org/10.1016/j.cogdev.2007.02.001

Hinton, L. (2001). The master-apprentice language learning program. In L. Hinton \& K. Hale (Eds.), The green book of language revitalization in practice, 217-226. Academic Press.

Galla, C. K. (2016). Indigenous language revitalization, promotion, and education: Function of digital technology. Computer Assisted Language Learning, 29(7), 1137-1151. https://doi.org/10.1080/09588221.2016.1166137 
Kahtehrón:ni, I. S. (2016). Second language speakers and language revitalization in Kahnawà:ke (Unpublished master's thesis). University of Victoria.

National Association of Friendship Centres (NAFC). (2018). Our languages, our stories: Towards the revitalization and retention of Indigenous languages in urban environments. Department of Canadian Heritage. https://sencanada.ca/content/sen/committee/421/APPA/Briefs/DiscussionPaper_NAFC_e.pdf

Ontario Federation of Indigenous Friendship Centres (2015). Gidizhigiizhwewinaanan (our languages): Language transfer practices in urban indigenous communities. https://ofifc.org/?research=gidizhigiizhwewinaanan-our-languages-languagetransfer-practices-in-urban-indigenous-communities-2015

Rorick, L. (2018). Wałya?asuk?i naananiqsakqin: At the home of our ancestors: Ancestral continuity in Indigenous land-based language immersion. In L. Smith, E. Tuck \& K. Yang (Eds.), Indigenous and decolonizing studies in education. (pp. 224-237). Routledge. https://doi.org/10.4324/9780429505010

Rosborough, P. C. (2012). K'angextola sewn-on-top: Kwak'wala revitalization and being Indigenous (Unpublished doctoral dissertation). University of British Columbia, Vancouver.

Rosborough, T. (2019, Feb 5). Trish Rosborough speaks Kwak'wala [Audio podcast]. First words : Unreserved. CBC radio.

Rosborough, T., \& Rorick, L. (2017). Following in the footsteps of the wolf: Connecting scholarly minds to ancestors in Indigenous language revitalization. AlterNative: An International Journal of Indigenous Peoples, 13(1), 11-17. https://doi.org/10.1177/1177180116689031

Rosborough, T., Rorick, L., \& Urbanczyk, S. (2017). Beautiful words: Enriching and Indigenizing Kwak'wala revitalization through understandings of linguistic structure. The Canadian Modern Language Review/La Revue Canadienne des Langues Vivantes 73(4), 425-437. https://www.muse.jhu.edu/article/678834

Statistics Canada. (2016). Aboriginal people in Canada: Key results from the 2016 census. https://www150.statcan.gc.ca/n1/daily-quotidien/171025/dq171025a-eng.htm

Thompson, J. C. (2012). Hedekeyeh hots'ih kahidi, Our ancestors are in us: Strengthening our voices through language revitalization from a Tahltan worldview (Doctoral dissertation, University of Victoria). https://dspace.library.uvic.ca/handle/1828/4213 
United Nations Educational, Scientific and Cultural Organization (UNESCO) (2019). Spoken from the heart: Indigenous radio in Canada. https://en.ccunesco.ca/-/media/Files/Unesco/Resources/2019/08/SpokenFromTheHeartIndigenousRadioInCanada.pdf

Wildcat, M., McDonald, M., Irlbacher-Fox, S., \& Coulthard, G. (2014). Learning from the land: Indigenous land based pedagogy and decolonization. Decolonization: Indigeneity, Education \& Society, 3(4), 1-15. https://jps.library.utoronto.ca/index.php/des/article/view/22248

Wilson, D. (2016). Aboriginal radio station to revive K'omoks language. CBC News. https://www.cbc.ca/news/canada/british-columbia/campbell-river-homalco-aboriginal-radio-station-1.3821253 